\title{
Annealing of Shot Peened Austenitic Superheater Tubes and Its Consequences for Steamside Oxidation
}

\author{
Pantleon, Karen; Lampert, Felix; Montgomery, Melanie
}

Published in:

Metallography, Microstructure, and Analysis

Link to article, DOI:

$10.1007 / \mathrm{s} 13632-020-00666-x$

Publication date:

2020

Document Version

Peer reviewed version

Link back to DTU Orbit

Citation (APA):

Pantleon, K., Lampert, F., \& Montgomery, M. (2020). Annealing of Shot Peened Austenitic Superheater Tubes and Its Consequences for Steamside Oxidation. Metallography, Microstructure, and Analysis, 9, 603-614. https://doi.org/10.1007/s13632-020-00666-x

\section{General rights}

Copyright and moral rights for the publications made accessible in the public portal are retained by the authors and/or other copyright owners and it is a condition of accessing publications that users recognise and abide by the legal requirements associated with these rights.

- Users may download and print one copy of any publication from the public portal for the purpose of private study or research.

- You may not further distribute the material or use it for any profit-making activity or commercial gain

- You may freely distribute the URL identifying the publication in the public portal 


\title{
Annealing of shot peened austenitic superheater tubes and its consequences for steamside oxidation
}

Karen Pantleon, Felix Lampert*, Melanie Montgomery ${ }^{*}$

Technical University of Denmark, DK-2800 Kongens Lyngby, Denmark

Department of Mechanical Engineering, Produktionstorvet, building 425

*now at: SABIC Limburg B.V., Geleen, The Netherlands.

\#now at: Siemens Gamesa, Brande, Denmark.

\begin{abstract}
Surface modifications offer promising solutions to increase the lifetime and performance of superheaters in industrial applications. The surface and internal structure of the steamside of austenitic superheater tubes of TP347H austenitic stainless steel was modified by shot peening and the thermal stability of the microstructure at the surface was followed in-situ and ex-situ during subsequent isothermal annealing. At various industrially relevant temperatures, the kinetics of microstructure evolution near the surface was investigated by applying complementary methods of microscopy and diffraction analysis. The beneficial effect of shot peening on reducing steamside oxidation was confirmed both on laboratory scale mimicking the real industrial conditions and after long term exposure to steam oxidation conditions in a thermal power plant. Both the effect of the grain size in austenite and the role of shot peening on steam oxidation are discussed.
\end{abstract}




\section{Introduction}

Superheater tubes in thermal power plants suffer from steamside oxidation on the inner concave side of the tube. A duplex oxide layer forms, which consists of both an outward grown iron based oxide (hematite and magnetite) and an inward grown $\mathrm{Fe}-\mathrm{Cr}$-Ni oxide resulting from internal oxidation of the material. The original metal surface usually defines the interface between the outer and the inner oxide layers. In power plants, where the superheaters are long-term exposed at operating temperatures of about $560{ }^{\circ} \mathrm{C}$, the oxide grows in thickness as a function of time and with increasing oxide thickness, the risk of oxide spallation increases. When the steam flow in the loops is blocked by exfoliated flakes of the oxide, failure of the superheater tubes due to overheating can occur. The spalled oxide can also be transported by the steam towards the turbine and cause severe erosion damage. Numerous studies on the growth mechanisms and kinetics of steamside oxidation have been undertaken considering the alloy composition and microstructure as well as exposure conditions like temperature, pressure and gaseous atmosphere in the power plants, e.g. [1-5].

For ultra supercritical superheater tubes, austenitic stainless steels containing about 18 wt.\% chromium are preferred compared to ferritic-martensitic steels, because they can be subjected to higher steam temperatures and provide better long-term high-temperature corrosion resistance [6]. Initially a passive layer of a chromium rich oxide forms at the surface and protects austenitic steels from further steam induced oxidation in the power plant, i.e. it prevents the outward growth of ironrich oxides. However, if that layer breaks down due to cracking, its self-healing capability cannot be maintained, because chromium was consumed at the very surface for the build-up of the layer and its slow diffusion from the bulk towards the surface cannot maintain the protective chromium rich oxide. As a consequence, a duplex oxide forms. Oxide spallation is a more serious problem for austenitic steels compared with ferritic-martensitic steels, because of the significant differences of the thermal expansion coefficients of austenite and iron oxides. 
To ensure formation of a protective continuous chromia layer on austenitic boiler steels, enhanced diffusion of chromium towards the surface is required. To that end, dedicated fine-grained austenitic steels, e.g. TP347HFG, with considerably improved oxidation resistance have been developed [7-10]. Grain refinement is obtained by a dedicated solution heat treatment with the subsequent formation of fine precipitates of niobium carbides, which efficiently hinder grain growth. The grain boundaries act as fast diffusion paths for chromium diffusion towards the surface, which favors the formation of a continuous chromium rich Fe-Cr oxide during service of fine-grained steels compared to coarsegrained steels. An alternative and/or additional strategy to promote the formation of a chromium rich protective oxide layer on the steamside surface is considered by introducing further lattice defects by means of a mechanical treatment of the superheater tubes prior to high-temperature exposure. Technologically feasible, although challenging, is shot peening of the inner side of the tubes. Surface modifications of steel induced by shot peening are rather well understood and the process is frequently applied to obtain compressive residual stresses for offsetting applied tensile stresses in the near surface region, e.g. [11]. The depth of the affected zone strongly depends on the shot peening parameters and covers up to several hundreds of micrometers. Shot peening yields plastic deformation of the material, thus, its main effect is the increase of the dislocation density. Furthermore, the transformation of the original microstructure into ultra-fine or even nanocrystalline grains is reported [10,12-15] and, therefore, severe shot peening has been recognized as a potential process for the fabrication of nanostructured materials with unique surface properties [16-21].

Significant grain refinement at the topmost surface and the associated formation of depth gradients of the grain size distributions within the shot peened surface region, in addition to enhanced diffusion via the dislocations, should provide short-circuit diffusion paths for rapid diffusion of chromium towards the surface. The microstructure of mechanically treated materials containing an increased number of lattice defects (dislocations, but also (sub-)grain boundaries and twin boundaries in case 
of austenite), however, is expected to be thermodynamically unstable and microstructure alterations may occur at operating temperatures of the superheaters in the power plants. Obviously, the formation of a protective chromium rich oxide competes with the annihilation of lattice defects at operation conditions. Hence, the beneficial effect of shot peening requires i) that the intentionally introduced lattice defects in the shot peened surface region remain efficient during long time exposure at high temperature or ii) that the chromium rich oxide layer forms fast and thick enough to remain protective during operation of the power plant. Otherwise, as a function of time and temperature, the advantage of the original highly deformed surface can diminish and related microstructure changes may cause thicker oxides, which result in subsequent spallation and above-mentioned problems with blockage of the flow and carryover of oxide flakes to the turbine. The thermal stability of the shot-peened microstructure, which relates to the evolution of lattice defects, changes of both the size and the orientation of grains as well as possible phase transformations near the surface, is essential for the final high-temperature performance with respect to steamside oxidation.

The beneficial effect of shot peening on retarding steam oxidation resulting in reduced thicknesses of the steamside oxide has been confirmed during both laboratory studies [3] and field exposure of shot peened superheaters [7,22] compared to not shot peened tubes. The convincing results of the improved resistance against steam oxidation triggered the installation of shot peened tubes as test segments for long-term exposure in Danish power plants. From an application point of view, shot peening of superheater tubes is known to have a beneficial effect, which, however from a scientific point of view, is not fully understood yet. The present work is dedicated to the deeper understanding of microstructure changes during high-temperature exposure of austenitic superheater tubes with and without shot peening of the surface. Samples from real superheater tubes (fine-grained and coarse grained tubes) with and without shot peening were used for laboratory investigations including systematic annealing studies and subsequent exposure to steam oxidation conditions. The 
complementary use of microscopy and diffraction analysis revealed the kinetics of microstructure evolution during isothermal annealing and the response of different annealing states on steam oxidation. Results from the systematic lab-scale treatments are complemented with the investigation of initially identical but long-term plant-exposed samples from a Danish thermal power plant.

\section{Experimental details}

\subsection{Superheater tubes}

Austenitic stainless steel TP347H was investigated. Its chemical composition, as given in Table 1, was determined by energy dispersive X-ray spectroscopy (EDS) applying a scanning electron microcope JSM-5900 from Jeol with an Inca Wave EDS detector from Oxford Instruments. Real superheater tubes were available in both a coarse-grained (CG) and a fine-grained (FG) version. Grain sizes of the coarse-grained TP347H-CG tubes correspond to ASTM grain size number 6 (about 45 $\mu \mathrm{m}$ on average), whereas the fine-grained TP347H-FG tubes consist of grain sizes according to ASTM 8 (about $22 \mu \mathrm{m}$ on average). The fine-grained and coarse-grained steel tubes, obviously, are not from the same batch, but the chemical composition of both types of TP347H is well within the steel specification as shown in Table 1. The shot peened and not shot peened samples of each steel type originate from the same fine-grained and coarse-grained tube, respectively, and therefore are identical in chemical composition.

For both the fine-grained and the coarse-grained versions of $\mathrm{TP} 347 \mathrm{H}$, seamless superheater tubes were available with and without shot peening at their inner (steamside) surface. As the superheater tubes were delivered in their final state ready for applications in the thermal power plant, i.e. with and without shot peening, respectively, details about the shot peening process are not available. Therefore, the present study is not addressed primarily to the microstructure modifications as a result of the applied mechanical treatment, but rather focuses on the thermal stability of the internal structure 
induced by shot peening and its final effect on steam oxidation in comparison to virgin, not shot peened samples of the same steels. Samples of the present study are in terms of the material, microstructure, surface topography and geometry identical to the superheater tubes currently installed commercially (without shot peening) or in test segments (with shot peening) in Danish thermal power plants.

The superheater tubes with an outer diameter of $33 \mathrm{~mm}$ and a wall thickness of $5.6 \mathrm{~mm}$ were cut into rings of $10 \mathrm{~mm}$ thickness, which were further cut into segments for high-temperature exposure in the laboratory and subsequent materials characterization. For comparison of laboratory-scale experiments with long-term field exposure under industrial conditions, superheater tubes exposed in a thermal power plant were also cut into segments for microstructure analysis.

\subsection{High-temperature exposure}

The investigation of the thermal stability of the microstructure was mainly of interest for shot peened samples, but for comparison, also virgin samples without shot peening were exposed under identical conditions. Both isothermal annealing in inert atmosphere and steam oxidation experiments were carried out such that the concave surfaces of the samples, i.e. the inner side of the ring segments cut from the tubes, were pointed upwards in the furnaces. Before high-temperature exposure, samples were degreased in acetone and finally cleaned with ethanol.

\subsubsection{Isothermal annealing}

In order to study solely microstructure changes induced by temperature, isothermal annealing occurred in an oxygen-free atmosphere. To this end, the annealing furnace was evacuated and flushed with argon for several hours before each experiment. Isothermal annealing was carried out in either vacuum or an argon atmosphere and, in the latter case, samples were additionally wrapped in stainless steel foil to avoid any risk of oxidation. 
In the furnace, annealing was carried out at various isothermal temperatures in the range of $400{ }^{\circ} \mathrm{C}$ to $700{ }^{\circ} \mathrm{C}$. While at $400{ }^{\circ} \mathrm{C}$ and $700{ }^{\circ} \mathrm{C}$ a single holding time of $0.5 \mathrm{~h}$ was applied, annealing at $550{ }^{\circ} \mathrm{C}$, $600{ }^{\circ} \mathrm{C}$ and $650{ }^{\circ} \mathrm{C}$ was carried out for the fine-grained steel as a function of holding time amounting to $0.5 \mathrm{~h}, 1 \mathrm{~h}, 2 \mathrm{~h}, 4 \mathrm{~h}, 6 \mathrm{~h}$ and $12 \mathrm{~h}$. Thus, the kinetics of microstructure evolution could be followed at temperatures, which are most relevant for thermal power plants. At each combination of annealing time and temperature, a new sample was exposed and, accordingly, the results of microstructure analysis before and after exposure correspond to ex-situ investigations.

Such ex-situ (furnace) annealing was supplemented with an in-situ analysis of the kinetics of isothermally occurring microstructure changes by applying a heating stage in an X-ray diffractometer. Such in-situ annealing was carried out at $580{ }^{\circ} \mathrm{C}$, where XRD patterns were repeatedly recorded for one and the same sample over a total time of up to $55 \mathrm{~h}$. For comparison, both a shot peened and a not shot peened sample of the fine-grained steel were subjected to in-situ annealing studies.

\subsubsection{Steam oxidation}

Both as-received and isothermally annealed samples were further exposed to steam oxidation conditions. The humidified environment, which superheater tubes experience in thermal power plants, was mimicked on laboratory scale in a dedicated steam oxidation furnace. A tube furnace was flushed with argon for $24 \mathrm{~h}$ prior to exposure of the samples. Argon was used as carrier gas and was humidified by bubbling it through deionized water at a temperature of $80{ }^{\circ} \mathrm{C}$ at atmospheric pressure resulting in a steam content of $46 \%$; the experimental setup is described in [2]. Samples were exposed to this steam atmosphere and kept at a temperature of $650{ }^{\circ} \mathrm{C}$ for the period of $168 \mathrm{~h}$. Cooling to room temperature occurred slowly while keeping the samples inside the furnace to avoid spallation of oxides. 
The various high-temperature exposed samples of $\mathrm{TP} 347 \mathrm{H}$ are labeled indicating the following information in the sample name: the type of steel being fine-grained (FG) or coarse-grained (CG), whether shot peening (SP) or no shot peening (NSP) of the surface was applied, the annealing conditions in terms of the isothermal temperature (in ${ }^{\circ} \mathrm{C}$ ) and the holding time (in $\mathrm{h}$ ) and, when applied, the subsequent steam oxidation exposure (+OX). For example, FG-SP-650-4+OX denotes a fine-grained sample of TP347H, which has been shot peened and annealed isothermally at $650{ }^{\circ} \mathrm{C}$ for $4 \mathrm{~h}$ prior to final exposure to steam oxidation conditions.

\subsection{Microstructure characterization}

The steamside, i.e. the inner side of the tubes, was of interest for microstructure characterization. The concave curvature of the surface gives particular challenges, because most characterization techniques rely on flat and smooth sample surfaces. In addition, the microstructure of the various samples in their as-received state with or without shot peening as well as microstructure changes initiated by both isothermal annealing and final steam oxidation were investigated. The resulting depth-dependent changes of the microstructure for all samples require complementary methods to reveal all aspects of interest.

For microscopic analysis, cross sections of the samples were embedded into epoxy and metallographically prepared by grinding and polishing down to $1 \mu \mathrm{m}$ diamond suspension. Etching was undertaken applying various etchants, including Kalling's reagent 1, glyceregia, and electrolytical etching with oxalic acid, to reveal the microstructure for reflected light optical microscopy (RLM) and scanning electron microscopy (SEM). For RLM, an Olympus GX41 microscope was used. SEM analysis was carried out with a Jeol JSM-5900 applying secondary electrons for imaging after carbon coating the surface to avoid charging. For those samples, which 
have been exposed to steam oxidation conditions, the possible formation of an oxide scale was investigated without any etching.

The same cross sections were also used for electron backscatter diffraction (EBSD) analysis; however, samples were re-prepared to ensure an artefact-free preparation for the surface sensitive analysis by applying a final preparation step of polishing with colloidal silica for the period of 5 minutes. To avoid charging of the non-conductive epoxy embedding during the EBSD analysis, the epoxy surface was manually covered with silver paint. Depending on the quality of the sample preparation and the quality of the silver painting in particular in the vicinity of the sample surface, the experimental parameters for recording EBSD maps were optimized for each sample. EBSD analysis was carried out in a dual beam SEM, a FEI Helios NanoLabTM 600 with an EDAX-TSL EBSD system and a Hikari camera. The SEM was operated applying an acceleration voltage of 15 $\mathrm{keV}$ and a beam current of $5.5 \mathrm{nA}$. EBSD maps were recorded with a step size of $100 \mathrm{~nm}$ and $4 \times 4$ binning. Only for the as-received sample, binning was reduced to $5 \times 5$, which allowed higher frame rates and, therefore, acquisition of a larger map.

X-ray diffraction (XRD) analysis was carried out directly on the concave surfaces using a Bruker AXS D8 Discover diffractometer operated with either $\mathrm{Cr}-\mathrm{K} \alpha$ (for in-situ annealing) or $\mathrm{Cu}-\mathrm{K} \alpha$ radiation (for ex-situ annealed and steam oxidized samples). In-situ XRD was carried out during isothermal annealing for the sake of line profile analysis while repeatedly measuring the austenite reflection 111 for the period of $55 \mathrm{~h}$ at a temperature of $580{ }^{\circ} \mathrm{C}$. Ex-situ XRD comprised both crystallographic texture analysis and line profile analysis including 111, 200, 220, 311, 222 and 400 reflections of austenite for as-received and heat treated samples. Peak fitting was carried out applying a pseudo-Voigt function, which revealed the position $2 \theta$, the integrated intensity $I_{\text {int }}$, the full-widthhalf-maximum $f$ and the shape factor $\eta$ indicating the Gaussian and Cauchy contribution to the 
measured peak profile. Based on the fitting results of $f$ and $\eta$, the integral breadth $\beta$ was calculated for the various diffraction lines and corrected for instrumental effects on line broadening. The integral breadth $\beta$ contains information about both the size of coherently diffracting domains and the microstrain, and, therefore, its change represents a direct measure for the occurring microstructure evolution. However, the separation of both contributions is required for quantification of the occurring changes and understanding the evolution of the internal structure. The in-situ XRD measurements of a single reflection only allowed for the application of the single line method [23,24], whereas the integral breadths obtained from ex-situ line profile analysis of multiple reflections were subjected to the Williamson-Hall method [25] to separate the influence of the size of coherently diffracting domains (interpreted as the crystallite size) and the microstrain. For samples, which had been further exposed to steam oxidation, XRD was applied for qualitative phase analysis.

Microhardness measurements were carried out on the above-mentioned metallographically prepared cross sections as a function of distance from the inner surface of the tube. Microhardness measurements in Vickers geometry were performed with a Future Tech FM-700 hardness tester applying a load of 5 gf. To ensure correct measurements unbiased by neighboring indents (i.e. following the Bückle rule) and at the same time allow for many closely spaced indents within the depth of interest, the microhardness indents were distributed on the cross section in various lines perpendicular to the concave sample surface, but each with different depths. Hardness values obtained from all the lines together finally give the depth-profile of the microhardness. In addition, also macrohardness indentations were carried out, but directly on the surface with concave curvature after flattening the convex backside of the sample for mechanical stability during testing. A Wolpert Dia Tester with a testing load of $20 \mathrm{~kg}$ was used. The measured macrohardness was corrected for the concave surface curvature according to DIN EN ISO 6507-1. 


\section{Results and Discussion}

\subsection{As-received samples: the effect of shot peening}

After shot peening, the inner side of the superheater tubes appears macroscopically with a typical hilland-valley topography. Microscopical characterization on cross sections of shot peened surfaces confirms this wavy topography and reveals slight local differences of the microstructure beneath the surface, although a direct relation to the hill-and-valley topography is not obvious.

For the fine-grained shot peened steel TP347H-FG, both RLM (covering larger sample areas) and EBSD (on rather local scale) indicate 3 different zones of the microstructure as a function of distance from the surface (Figure 1):

- Zone (i) forms at the very near surface down to a depth of about $15 \mu \mathrm{m}$, where grains cannot be resolved by RLM (see Figure 1a) and SEM. EBSD does not allow indexing in this zone indicating a nanocrystalline and heavily deformed region (Figure 1b). This is confirmed by XRD, which reveals considerably broadened peaks for shot peened surfaces as shown in Figure 2a on the example of the 111 reflection of austenite. Quantification of the line broadening yields, averaged over all grain orientations, small grain sizes of $15 \mathrm{~nm}$ and high microstrain of $5.110^{-3}$ for the topmost surface of the shot peened sample (FG-SP). In contrast, the narrower peaks of the sample without shot peening (FG-NSP) correspond to crystallite sizes above $300 \mathrm{~nm}$ (being the detection limit of XRD determination of the coherently diffracting domain size) and lower microstrains of $2.110^{-4}$. XRD texture analysis does not indicate a pronounced preferred orientation, in agreement with literature, reporting nanocrystalline equiaxed grains of random orientation at the surface of shot peened steel [16].

- Zone (ii) continues down to a depth of about $200 \mu \mathrm{m}$, where deformation lines and orientation gradients are visible for many grains by RLM and EBSD, respectively (Figure 1). 
- Zone (iii) represents the bulk in larger depth, which remained unaffected by shot peening.

These gradual changes of the microstructure are also reflected in the microhardness measurements shown in Figure $2 \mathrm{~b}$. The depth profile measured for the shot peened sample indicates a rather sudden drop of microhardness within the first $100 \mu \mathrm{m}$, while at larger depths, the microhardness further decreases slowly towards the unaffected bulk. Comparison with a not-shot peened sample indicates that the mechanically modified surface region of the fine-grained steel comprises a total thickness of about $220 \mu \mathrm{m}$, which is in good agreement with microscopy results.

In the same way, the coarse-grained steel TP347H-CG exhibits similar changes of the microstructure with depth as a result of shot peening: Zone (i) at the topmost surface consists of very small grains, which can hardly be resolved by RLM (Figure 3a). In contrast to TP347H-FG, this zone extends to a slightly larger depth of more than $20 \mu \mathrm{m}$ for the coarse-grained steel. Also zone (ii) with visible deformation lines down to a depth of $250 \mu \mathrm{m}$ is deeper in the coarse-grained steel, and that difference of shot peening for the fine- and coarse-grained steel agrees with previous reports for another type of steel [10]. More obvious than for the fine-grained steel are some typical signs of deformation, which are visible in some of the grains of the coarse-grained steel (Figure 3a). These regions with dark needles refer to the presence of strain-induced martensite, which has formed during shot peening and is confirmed by XRD measurements. As indicated in Figure 3b, bcc $\alpha$-Fe reflections originating from ferrite/martensite are detected, although of low intensity and due to peak overlap mainly visible as an asymmetry of the austenite 111 reflection. Apart from peak asymmetry, the broadening of the 111 reflection due to shot peening is almost as high as measured for the fine-grained sample (cf. Figs. 2a and $3 \mathrm{~b}$ ), resulting in nanocrystalline grains of about $13 \mathrm{~nm}$ and high microstrain of $3.210^{-3}$ on average over all grain orientations at the shot peened surface of the coarse-grained steel. Zone (iii) in larger depth represents the bulk of TP347H-CG, which remained unaffected by shot peening. Shot-peening of the coarse-grained steel, similarly as observed for the fine-grained steel (cf. Fig. 2b), results in a 
considerable increase of the microhardness at the surface and a pronounced hardness depth-profile, as shown in Figure 3c.

\subsection{Effect of isothermal annealing on fine-grained TP347H with and without shot peening}

After annealing, the original shot peened region of the fine-grained steel is marked by precipitates, which form both along the grain boundaries and in the grain interiors. The surface region with precipitates extends to deeper depth with increasing time or temperature of annealing (see examples in Figure 4), but no precipitates have been observed beyond the original depth affected by shot peening. Thus, formation of these precipitates during annealing is driven by the enhanced diffusion due to the high density of lattice defects originating from shot peening. These precipitates are presumably carbides, but their small, although varying, dimensions down to nanometer sizes prevent their chemical identification by the applied methods.

The formation of these precipitates should yield an increase in the surface hardness of annealed samples, which, however, has been confirmed experimentally only in case of low annealing temperatures $\left(400{ }^{\circ} \mathrm{C}\right)$ and/or short annealing times $(0.5 \mathrm{~h})$. At higher temperatures and longer annealing, a reduction of microhardness has been measured at the very near surface. This is shown in Figure 5 on the example of samples annealed at $650{ }^{\circ} \mathrm{C}$ for different times and reflects that the expected hardness increase due to the formation of precipitates obviously is more than balanced by a counteracting effect, which lowers the hardness of the shot peened surface in the course of annealing.

The observation that the largest drop in hardness occurred directly at the surface in zone (i) (i.e. the region of smallest grain size and highest microstrain after shot peening) indicates that hardness reducing effects are more pronounced in those regions, where initially the density of lattice defects after shot peening and, thus, the driving force for microstructure changes was highest. The underlying mechanism of these microstructure changes has further been investigated by diffraction analysis. 
In-situ annealing of a shot peened sample of the fine-grained steel (FG-SP) in the diffractometer revealed that the broadening of XRD peaks decreases as a function of time at isothermal annealing temperature of $580{ }^{\circ} \mathrm{C}$, whereas no changes of peak broadening were observed during the same insitu annealing of a not-shot peened sample (FG-NSP). This is shown in Figure 6a by the evolution of the integral breadth on the example of the 111 peak of austenite, which has been followed in-situ during annealing. Major changes for the shot peened sample are observed within the first 10 hours of isothermal annealing, but even after $55 \mathrm{~h}$ at $580{ }^{\circ} \mathrm{C}$ the integral breadth does not reach the values of the not-shot peened samples (Figure 6a), thus, a considerable amount of deformation is still left and further evolution of the microstructure is ongoing.

Ex-situ investigations, i.e. XRD measurements of samples annealed in a conventional furnace, confirm the trend of decreasing integral breadth with annealing time. The use of various annealing temperatures furthermore reveals the temperature influence on the peak broadening, as shown in Figure 6b.

Figure 6 shows that the kinetics of the evolution of XRD peak broadening, as observed for shot peened samples during both in-situ and ex-situ isothermal annealing, follows a logarithmic time dependence, independent of the applied temperature. Such kinetics is typical for recovery [26]. In contrast, attempts to describe the observed evolution of the integral breadth obtained from XRD measurements by means of the Johnson-Mehl-Avrami-Kolmogorov kinetics [26] fail, which indicates that recrystallization did not occur, at least not within the annealing time applied in the present study. The decrease of the integral breadth is more severe with increasing annealing temperature and, independent of the temperature, it continues with prolonged annealing time (cf. Figure 6b). Quantification of the observed time- and temperature-dependent changes of the XRD peak broadening in terms of crystallite growth and relaxation of microstrain during annealing, as shown in Figure 7, is consistent with expected microstructure changes due to recovery, as suggested from the 
overall kinetics. In agreement with the conclusions from the in-situ investigations, also the ex-situ annealed samples approach the larger grain size and lower microstrain of the non-shot peened sample, but some effect of shot peening remained even after long-term annealing (up to $12 \mathrm{~h}$ ) at high annealing temperature $\left(650^{\circ} \mathrm{C}\right)$. After annealing, the original shot peened samples are still distinctly different from the non-shot peened samples.

The XRD data do not indicate the formation of any preferred grain orientations during annealing, which is also not expected for recovery. The shot peened surfaces after annealing are still of almost random grain orientation, as confirmed by XRD and suggested from the recorded EBSD maps. Compared to the as-received shot peened surface (cf. Figure 1b), EBSD analysis of annealed samples reveals only slight changes in the orientation of grains before and after annealing (see one example in Figure 8), which however may be related to the heterogeneity of shot peening along the surface and, consequently, resemble inadequate grain statistics in the small EBSD maps. Figure 8 also shows that the majority of grains after annealing still show typical signs of shot peening, which are visible either as pronounced orientation gradients within individual grains or still non-indexed regions. Remarkable are changes occurring in the outermost surface along the whole sample after long time annealing at high temperature (corresponding to $12 \mathrm{~h}$ at $650{ }^{\circ} \mathrm{C}$ of the present study, cf. Figure 8): Zone (i), which in the as-received state was characterized by very low image quality and grain sizes below the resolution limit of EBSD, changed considerably by annealing. In agreement with the strong decrease in microstrain (cf. Figure 7), the image quality of EBSD patterns recorded from that annealed surface improved considerably and grains can easily be resolved in the EBSD map (see Figure 8).

In order to exclude any artefacts due to sample preparation, contamination or oxidation, which would provoke misinterpretation of that fine-grained region at the surface, the annealed sample has been further investigated using RLM and SEM with particular focus on revealing the surface region and the nature of the small grains. To this end, the same annealed sample, which previously had been used 
for EBSD (cf. Figure 8), has been re-prepared metallographically, finished with OPS-polishing and etched by testing different etching solutions (e.g. glyceregia, Kallings), as shown in Figures 9a and b. Despite the different response of the sample to the various etching solutions, it is revealed that annealing at $650{ }^{\circ} \mathrm{C}$ has provoked grain growth at the very near surface of shot peened samples resulting in grain sizes of about $2 \mu \mathrm{m}$. These grains now can be resolved with SEM (Figure 9) and EBSD (Figure 8), because they are considerably larger than the original nanocrystalline grains at the shot peened surface, although still smaller than the grains further below the surface. In addition to the annealed sample with $12 \mathrm{~h}$ of isothermal holding at $650{ }^{\circ} \mathrm{C}$ in argon, also a sample exposed to an oxidizing atmosphere at $650{ }^{\circ} \mathrm{C}$ for a prolonged time of $168 \mathrm{~h}$ has been investigated to verify the grain growth, as shown in Figure 9c. Independent of the annealing treatment and the etching method, the presence of small, although not any longer nanocrystalline, grains at the very near surface was confirmed. The depth region of this small-grained zone at the surface comprises less than $10 \mu \mathrm{m}$ for annealing of $12 \mathrm{~h}$ in argon (cf. Figures 9a and b, in agreement with EBSD results in Figure 8) and expands to about $20 \mu \mathrm{m}$ depth with increased time of $168 \mathrm{~h}$ (cf. Figure 9c). Depending on the etching method, numerous fine precipitates were revealed in the surface near region of the annealed samples (cf. Figures $9 \mathrm{~b}$ and c). Metallographic preparation and etching has caused partial removal of these precipitates, leaving behind a porous surface. Figure 9 also emphasizes, in agreement with EBSD results in Figure 8, that microstructure changes occur mainly at the very near surface, while deeper regions below the surface still show the typical deformation signs of initial shot peening.

The increase of the subgrain size due to annealing as revealed by XRD (cf. Figure 7a) would not explain the visibility of the grains by microscopy (Figure 9) and EBSD (Figure 8), as the subgrains still are below the resolution limits of microscopy. Consequently, simultaneously to the evolution of subgrains, also grain growth must have happened during annealing. Although an increased grain size towards grain dimensions of about $2 \mu \mathrm{m}$, as in the present study, has been reported earlier for long- 
term and/or high-temperature annealing of shot peened austenitic stainless steel [10,14,27], the previously used terminology of recrystallization [10] cannot be confirmed based on the present results. The revealed kinetics of microstructure evolution, as measured by XRD (Figure 6), indicates that grain growth occurred for just recovered grains rather than for new recrystallized grains, which governs the mechanism of microstructure changes during annealing of the shot peened fine-grained steel.

\subsection{Effect of isothermal annealing on coarse-grained TP347H with and without shot peening}

Although only selected annealing experiments have been carried out for the coarse-grained steel, they reveal similar microstructure changes, as observed for the fine-grained steel. An annealing effect is only visible in the surface region of initial shot peening, while non-shot peened regions of the coarsegrained samples remain unaffected by annealing. Furthermore, and also consistent with fine-grained samples, annealing does not fully recover the microstructure and some shot peening effect remains within the surface. For example, annealing of the coarse-grained steel at $700{ }^{\circ} \mathrm{C}$ for $0.5 \mathrm{~h}$ results in an increased crystallite size of $138 \mathrm{~nm}$ and reduced microstrain of $1.210^{-3}$, and both values are still distinctly different compared to the sample without shot peening. Accordingly, also the microstructure clearly reveals that the shot peening effect still is visible after annealing, see Figure 10.

\subsection{Influence of shot peening on steam oxidation}

For samples without shot peening, the grain size of the steel has a huge influence on steam oxidation (see Figures 11a and b). During long-term exposure for $17000 \mathrm{~h}$ in a Danish power plant, the coarsegrained steels formed rather thick outer and inner oxide layers, while oxide layers on fine-grained steels are much thinner and oxides formed only locally along the surface. For the shot-peened samples, the grain size of the steels has no longer an effect on steam oxidation and both the fine- 
grained and the coarse-grained steels show considerably improved oxidation resistance as a result of shot peening (see Figures 11c and d). Independent of the grain size, both shot peened steels are almost free of oxidation at the surface.

While Figure 11 only indicates the presence or absence of an oxide layer, etching of the samples revealed details of the microstructure, as shown in Figure 12 for the laboratory annealed and subsequently steam oxidized samples. For both the fine-grained and the coarse-grained steels, the effect of shot peening is still visible at various locations along the surface even after one week exposure to steam oxidation conditions at $650^{\circ} \mathrm{C}$, although locally larger grains within the original nanocrystalline region of zone (i) have developed (see examples in Figures 12a and b). This heterogeneity along the surface, however, does not have a consequence for steam oxidation. In agreement with Figure 11, Figure 12 confirms that fine-grained, shot peened samples do not oxidize (Figure 12a), while only very local oxidation occurred during steam exposure of the coarse-grained shot peened steel (Figure 12b).

\section{Summary and Conclusion}

Commercially applied superheater tubes of austenitic stainless steel of the type TP347H have been investigated with the following objectives for understanding:

- the role of the steels' grain size, based on a fine-grained and a coarse-grained version

- the effect of shot peening, applied to the concave side of both the fine-grained and the coarsegrained steel tubes

- the mechanisms of microstructure evolution of the shot peened surfaces during annealing

- the response of the steels to steam oxidation, as a function of grain size and shot peening. 
Significant changes of the microstructure due to shot peening, for both the fine-grained and the coarse-grained steel, result in hardness-depth profiles and associated microstructure gradients within the shot peened surface region. High dislocation densities, as indicated by high microstrain and nanocrystalline (sub)grains, mark the very near surface region after shot peening, which evolves during subsequent annealing. Although an increased microhardness compared to samples without shot peening remains at the surface after annealing, the original shot peened surfaces are affected by annealing: The reduction of microstrain with simultaneous growth of the size of austenite grains is accompanied by the formation of fine precipitates in the shot peened surface region, which counterbalances an expected hardness reduction of the austenite phase. The kinetics of microstructure evolution in the austenite phase during annealing (as measured by XRD) indicates that recovery has occurred, while an interpretation towards recrystallization fails. Recovery, together with the obvious growth of the originally nanocrystalline grains during annealing (as revealed by SEM and EBSD) considerably modified the shot peened surfaces. Complementary methods of microstructure characterization using both diffraction analysis (XRD, EBSD) and microscopy (RLM, SEM), and further supplements by hardness measurements as a function of distance from the surface, as applied in the present study, are essential for the comprehensive understanding of all microstructure changes across the different length scales. Simultaneously to the occurring microstructure evolution of the austenite phase by shot peening and subsequent annealing, temperature induced precipitations occur predominantly within the shot peened regions. The role of precipitates and their relation to the evolving microstructure of austenite, however, has not been in focus for the present study.

Despite the revealed evolution of the shot-peened surfaces as a function of time and temperature, the shot peening effect does not diminish fully by annealing and the microstructure at the surface of originally shot peened samples still contains more lattice defects (dislocations, grain boundaries), which allow for fast diffusion of chromium towards the surface to form a thin chromia layer compared 
to not shot peened samples. Consequently, shot peened samples perform considerably better during exposure to steam oxidation conditions, and an exceptionally good steam oxidation resistance is observed for shot peened samples of both the fine-grained and the coarse-grained austenitic superheater tubes, compared to their not shot peened counterparts which clearly oxidized. While without shot peening, the fine-grained steel provides considerably better steam oxidation resistance compared to the coarse-grained material, the advantage of the fine-grained material is not obvious any longer when shot peening has been applied before high temperature exposure. This means that the costly fabrication of the fine-grained type of austenitic stainless steel TP347H, which requires a dedicated solution treatment to stabilize the fine grains by $\mathrm{Nb}$ precipitates, can be omitted when shot peening is contemplated in any case as a final processing step. Shot peening efficiently suppresses steam oxidation, even for coarse-grained steel, which contributes to enhancing the lifetime of superheater tubes and/or allows increasing the operation temperature of thermal power plants.

\section{Acknowledgement}

The authors are grateful to Richard Kemsies and Sunday Chukwudi Okoro, who carried out some of the experimental work. Furthermore, Alice Bastos Fanta and Hossein Alimadadi are kindly acknowledge for valuable discussions and support with EBSD. 


\section{References}

[1] Osgerby, S., Fry, A. T: Steam Oxidation Resistance of Selected Austenitic Steels. Materials Science Forum 461-464, 1023-1030 (2004).

[2] Hansson, A. N., Pantleon, K., Grumsen, F. B., Somers, M. A. J.: Microstructure evolution during steam oxidation of a $\mathrm{Nb}$ stabilized austenitic stainless steel. Oxidation of Metals 73, 289-309 (2010).

[3] Rosser, J. C., Bass, M. I., Cooper, C., Lant, T., Brown, P. D., Connolly, B. J., Evans, H. E.: Steam oxidation od Super 304H and shot-peened Super 304H. Materials at High Temperatures 29, 95$106(2012)$.

[4] Dudziak, T., Łukaszewicz, M., Simms, N., Nicholls, J.: Analysis of high temperature steam oxidation of superheater steels used in coal fired boilers. Oxidation of Metals 85, 171-187 (2016).

[5] Wright, I. G., Dooley, R. B.: Morphology of oxide growth and exfoliation in superheater and reheater tubing of steam boilers. Materials at High Temperatures 28, 40-57 (2011).

[6] Viswanathan, R., Bakker, W.: Materials for Ultrasupercritical Coal Power Plants-Boiler Materials: Part 1. Journal of Materials Engineering and Performance 10, 81-95 (2001).

[7] Matsuo, H., Nishiyama, Y., Yamadera, Y.: Steam oxidation property of fine-grain steels. Proc. from the Fourth Int. Conf. on Advances in Materials Technology for Fossile Power Plants, EPRI Report Number 1011381, 441-450 (2005). 
[8] Yoshikawa, K., Teranishi, H., Tokimasa, K., Fujikawa, H., Miura, M., Kubota, K.: Fabrication and properties of corrosion resistant TP347H stainless steel. J. Mater. Eng. 10, 69-83 (1988).

[9] Montgomery, M., Hede Larsen, O., Aakjær Jensen, S., Biede, O.: Field Investigation of Steamside Oxidation for TP347H. Materials Science Forum 461-464, 1007-1014 (2004).

[10]Nishiyama, Y., Iseda, A., Yoshizawa, M., Matsumoto, S., Igarashi, M.: Effect of Grain Size on Steam Oxidation for Shot-Peened Stainless Steels, Advances in Materials Technology for Fossil Power Plants: Proc. from the 6th Int. Conf., 185-197 (2011).

[11]Wang, S., Li, Y., Yao, M., Wang, R.: Compressive residual stress introduced by shot peening. J. Materials Processing Technology 73, 64-73 (1998).

[12]Bagherifard, S., Slawik, S., Fernández-Pariente, I., Pauly, C., Mücklich, F., Guaglianoa, M.: Nanoscale surface modification of AISI 316L stainless steel by severe shot peening. Materials and Design 102, 68-77 (2016).

[13]Fargas, G., Roa, J. J., Mateo, A.: Effect of shot peening on metastable austenitic stainless steels. Materials Science and Engineering A 641, 290-296 (2015).

[14] Pour-Ali, S., Kiani-Rashid, A. R., Babakhani, A., Virtanen, S.: Thermal stability of nanocrystalline surface layer of AISI 321 stainless steel. Vacuum 146, 297-303 (2017).

[15] Yinsheng H., Keun-Bong Y., Houyu M., Keesam S.: Study of the austenitic stainless steel with gradient structured surface fabricated via shot peening. Materials Letters 215, 187-190 (2018).

[16] Tao, N. R., Suib, M. L., Lud, J., Lua, K.: Surface nanocrystallization of iron induced by ultrasonic shot peening. NanoStructured Materials 11, 433-440 (1999). 
[17] Liu, J. L., Umemoto, M., Todaka, Y., Tsuchiya, K.: Formation of a nanocrystalline surface layer on steels by air blast shot peening. Journal of Materials Science 42, 7716-7720 (2007).

[18]Liu, W. B., Zhang, C., Xia, Z. X., Yang, Z. G., Wang, P. H., Chen, J. M.: Strain induced refinement and thermal stability of a nanocrystalline steel produced by surface mechanical attrition treatment. Materials Science and Engineering A 568, 176-183 (2013).

[19] W. Liu, C. Zhang, Z. Yang, Z. Xia: Microstructure and thermal stability of bulk nanocrystalline alloys produced by surface mechanical attrition treatment. Applied Surface Science 292, 556$562(2014)$.

[20] Todaka, Y., Umemoto, M., Watanabe, Y., Tsuchiya, K.: Formation of nanocrysstalline structure by shot peening. Materials Science Forum 503-504, 669-674 (2006).

[21] Wang, T., Yu, J., Dong, B.: Surface nanocrystallization induced by shot peening and its effect on corrosion resistance of 1Cr18Ni9Ti stainless steel. Surf. Coat. Techn. 200, 4777-4781 (2006).

[22] Husemann, R. U.: Materials and their service properties for superheater and reheater tubing in power stations with advanced steam parameters: Part 2: influence of oxidation and cold deformation, conclusions and recommendations. Vgb Powertech 79, 84-87 (1999).

[23]Langford. J. I.: A Rapid Method for Analysing the Breadths of Diffraction and Spectral Lines using the Voigt Function. J. Appl. Cryst. 11, 10-14 (1978).

[24]De Keijser, T. H., Langford, J. I., Mittemeijer, E. J., Vogels, A. B. P.: Use of the Voigt Function in a Single-Line Method for the Analysis of X-ray Diffraction Line Broadening. J. Appl. Cryst. 15, 308-314 (1982). 
[25] Williamson, G. K., Hall, W. H.: X-ray line broadening from filed aluminum and wolfram, Acta Metallurgica 1. 22-31 (1953).

[26]Humphreys, F.J., Hatherly, M.: Recrystallization and Related Annealing Phenomena, Pergamon, New York (1996).

[27] Xuanpei W., Zeyou Q., Zhiling Z., Hongcheng Z., WeijieW., Yanfei W.: Surface Grain Refinement of 304L Stainless Steel by Combined Severe Shot Peening and reversion annealing treatment. Coatings 10, 470-477 (2020). 


\section{Figures}
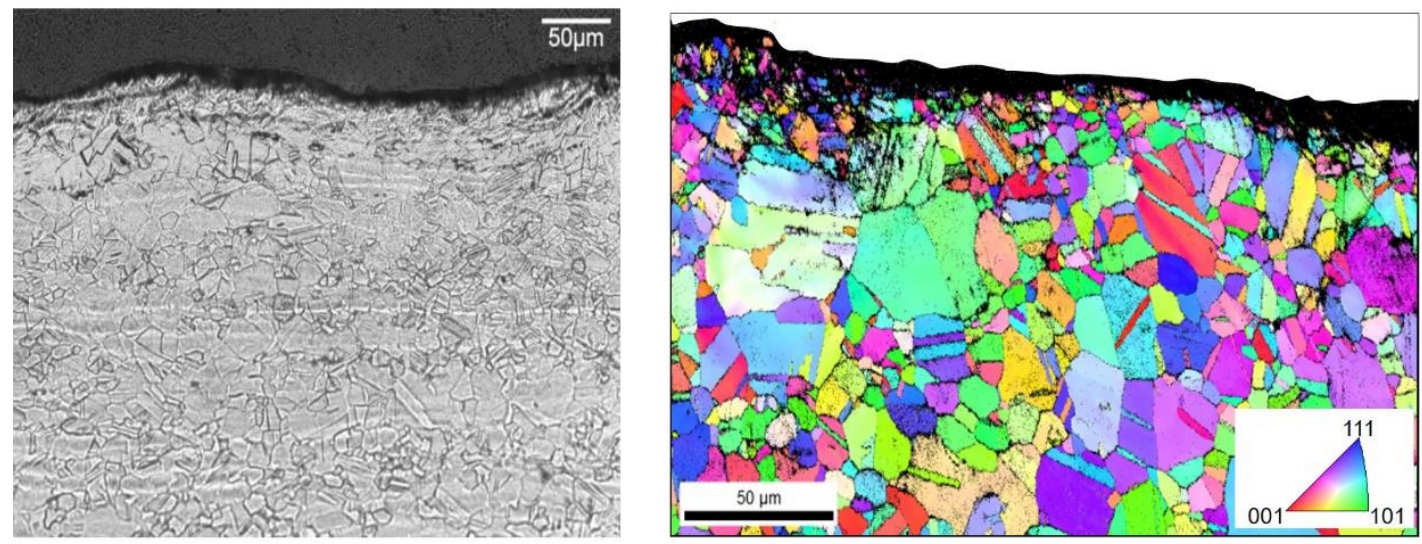

Figure 1: Microstructure of the cross section of as-received fine-grained steel after shot peening (sample FG-SP): a) RLM micrograph, b) EBSD map, IPF colored in ND; non-indexed regions are marked black.

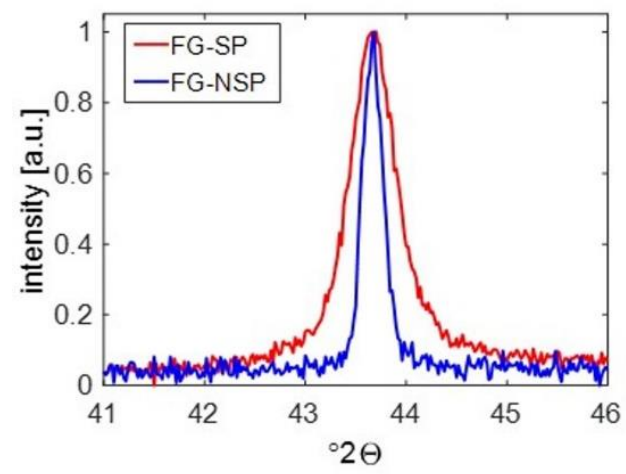

a)

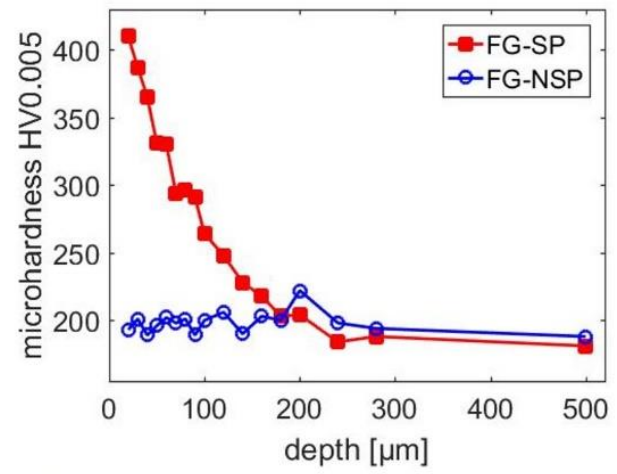

b)

Figure 2: Comparison of the fine-grained steel (FG-samples) with (SP) and without (NSP) shot peening: a) line profiles of the XRD 111 reflection of austenite and b) microhardness-depth-profiles.

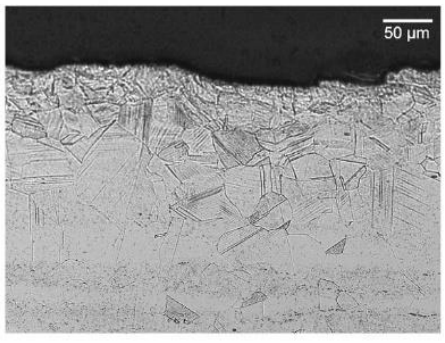

a)

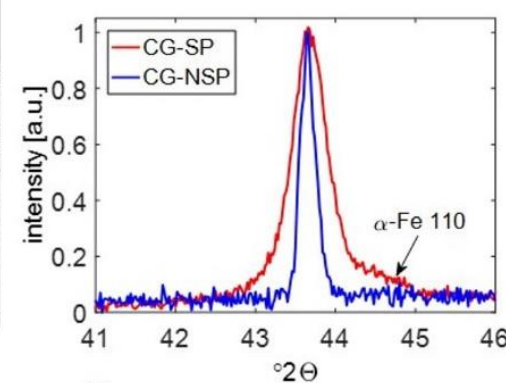

b)

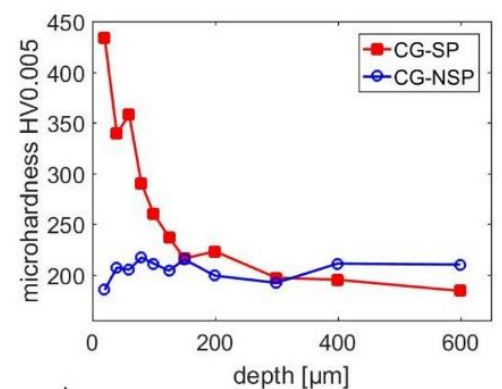

c)

Figure 3: As-received coarse-grained steel (CG-samples): a) RLM micrograph of the cross section of a shot peened sample CG-SP, b) XRD line profiles for samples with (SP) and without (NSP) shot peening indicating reflections of both austenite-111 and ferrite/martensite-110 in case of shot peening (-SP), c) microhardness-depth-profiles. 

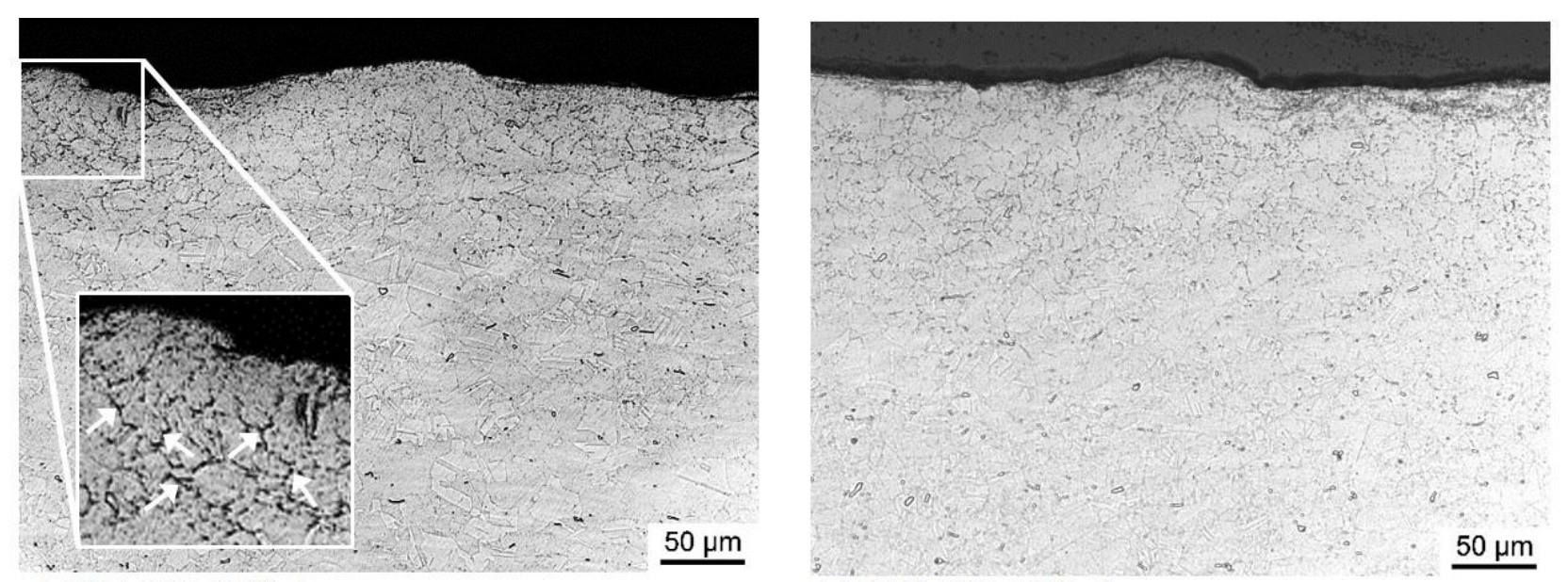

a) FG-SP-650-1

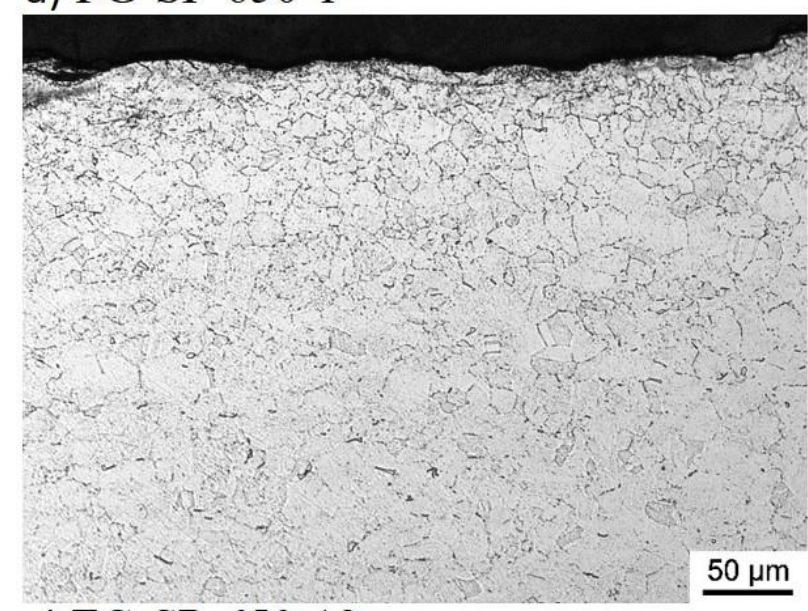

c) FG-SP-650-12

b) FG-SP-650-6

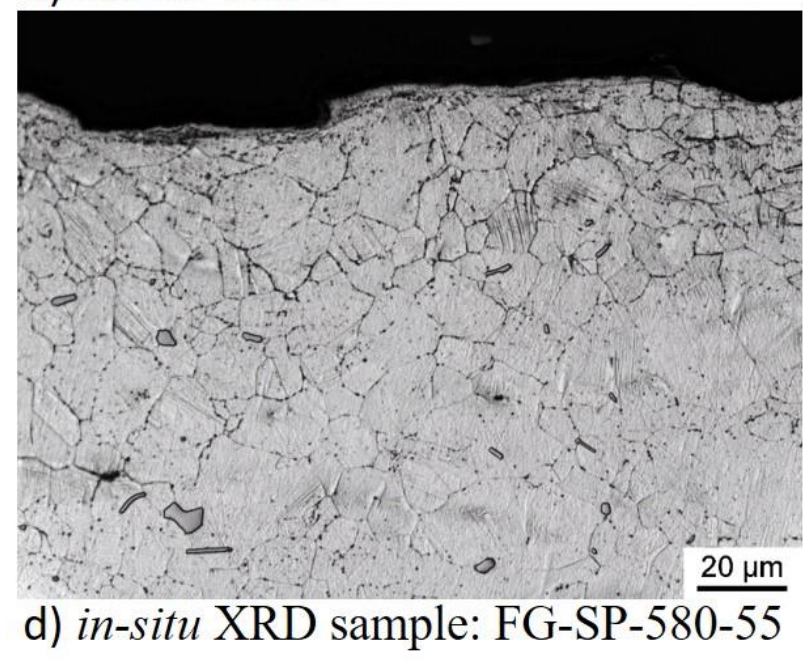

Figure 4: Microstructure of the cross section of the fine-grained, shot peened steel (samples FG-SP) after isothermal annealing in inert atmosphere: a-c) furnace annealing at $650{ }^{\circ} \mathrm{C}$ for different times (up to $12 \mathrm{~h}$ ), d) in-situ annealing during XRD at $580{ }^{\circ} \mathrm{C}$ for $55 \mathrm{~h}$. For visualization, some of the precipitates mentioned in the text are marked by arrows in the magnified insert in a).

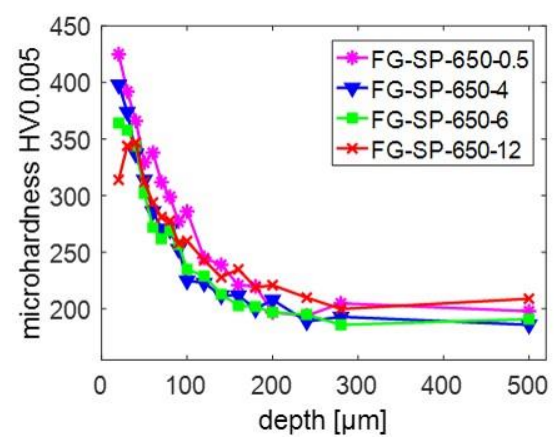

Figure 5: Microhardness depth profile of fine-grained, shot peened steel (samples FG-SP) annealed at a temperature of $650{ }^{\circ} \mathrm{C}$ for $0.5 \mathrm{~h}, 4 \mathrm{~h}, 6 \mathrm{~h}$ or $12 \mathrm{~h}$ (also samples after annealing for $1 \mathrm{~h}$ and $2 \mathrm{~h}$ confirm the drop of hardness near the surface, but are not shown here for visibility reasons). 


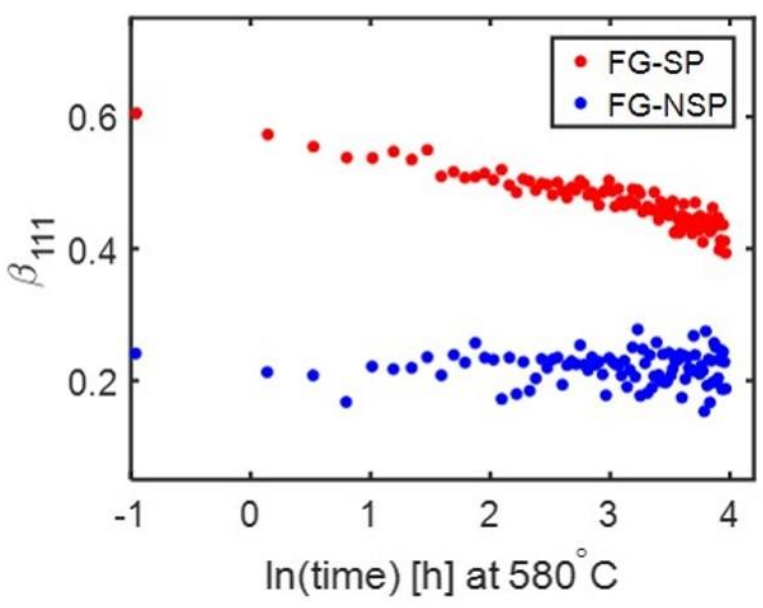

a)

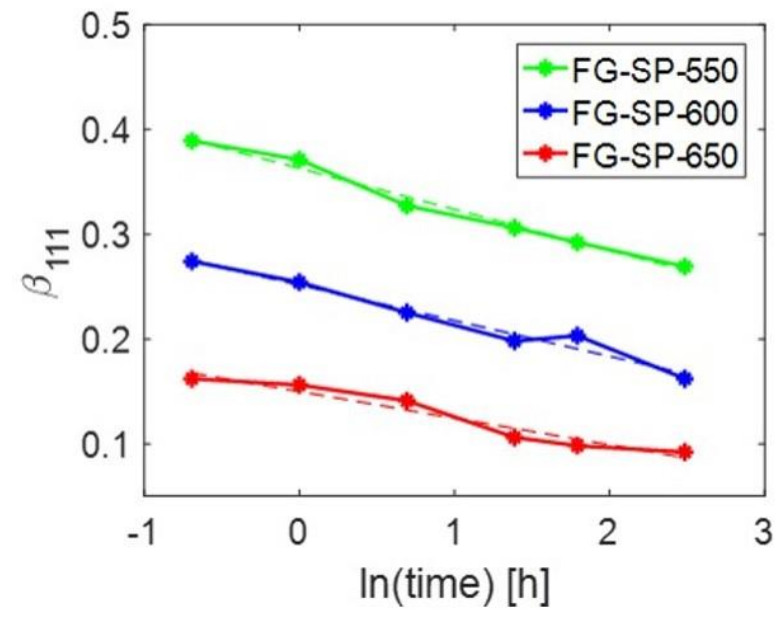

b)

Figure 6: Integral breadth $\beta$ of the 111 peak as a function of annealing time for fine-grained steel samples. a) in-situ isothermal annealing at $580{ }^{\circ} \mathrm{C}$ in the diffractometer, XRD patterns are recorded every $0.5 \mathrm{~h}$ over a total isothermal holding time of $55 \mathrm{~h} . \mathrm{b})$ ex-situ isothermal annealing as a function of isothermal holding time $(0.5 \mathrm{~h}, 1 \mathrm{~h}, 2 \mathrm{~h}, 4 \mathrm{~h}, 6 \mathrm{~h}, 12 \mathrm{~h})$ at various furnace temperatures $\left(550{ }^{\circ} \mathrm{C}\right.$, $600{ }^{\circ} \mathrm{C}, 650{ }^{\circ} \mathrm{C}$ ). Note: $\beta$-values in a) and b) cannot be compared with each other as different measurement conditions have been used (cf. section 2.3). Rather, the figures reveal the evolution of $\beta$ for one and the same sample.

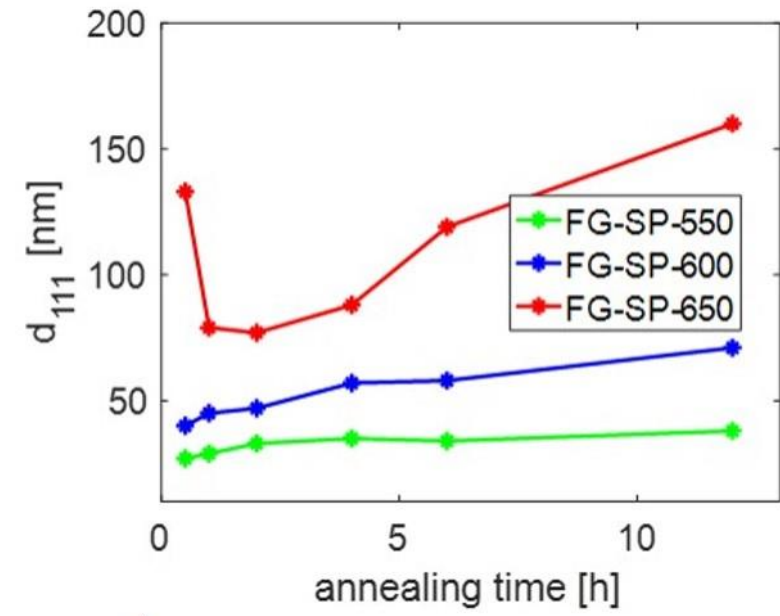

a)

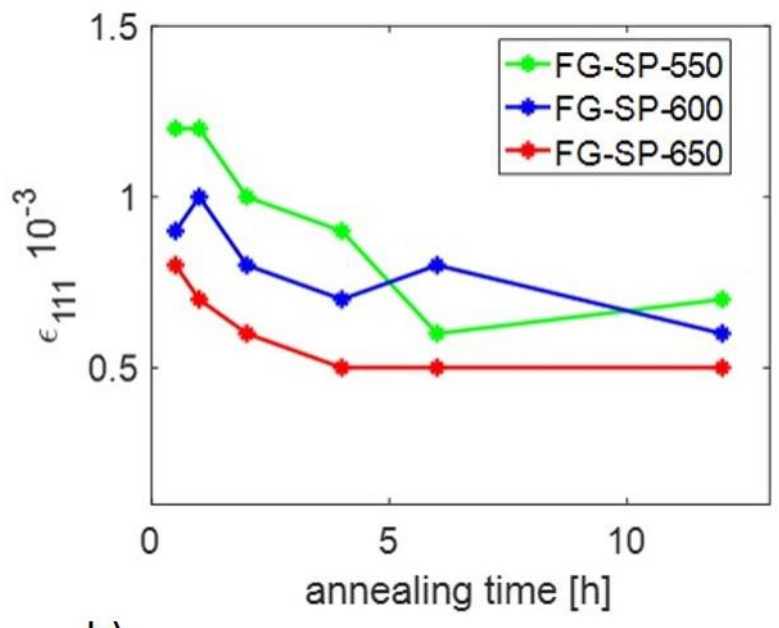

b)

Figure 7: Subgrain size d and microstrain $\varepsilon$ of $\langle 111\rangle$ oriented grains as a function of annealing time and temperature. For comparison, for the as-received shot peened sample $\mathrm{d}_{111}=17 \mathrm{~nm}$ and $\varepsilon_{111}=1.2$ $10^{-3}$ and for the as-received non-shot peened sample $\mathrm{d}_{111}>300 \mathrm{~nm}$ (detection limit) and $\varepsilon_{111}=0.2$ $10^{-3}$ have been determined. 


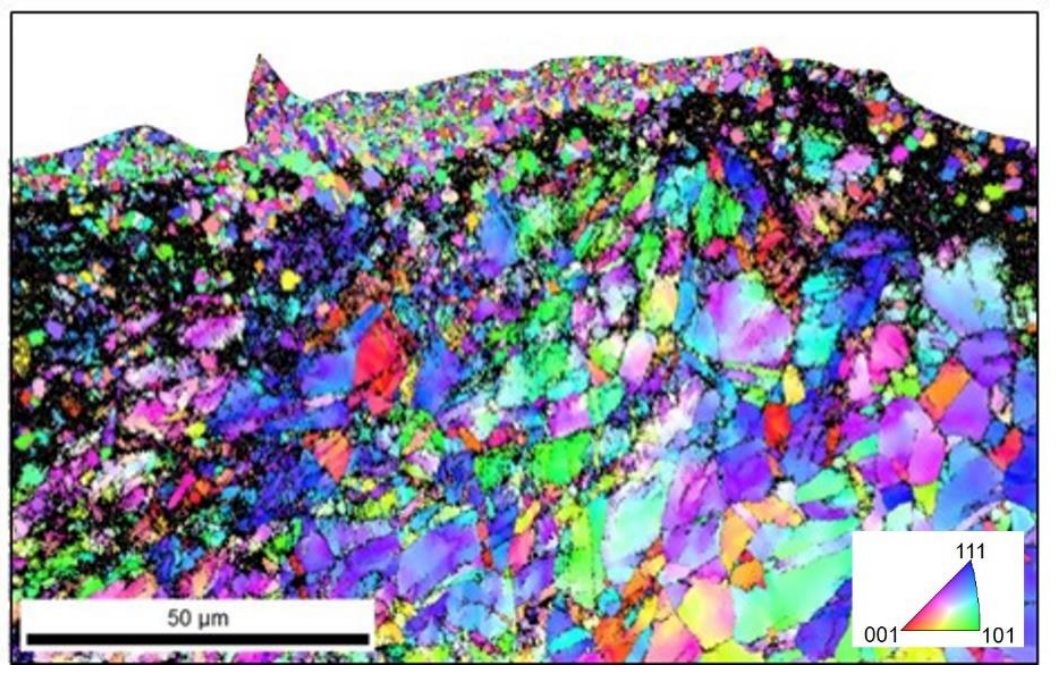

Figure 8: EBSD map after annealing of the shot peened, fine grained sample at $12 \mathrm{~h}$ at $650{ }^{\circ} \mathrm{C}$ (FGSP-650-12). The map is IPF colored in ND and non-indexed regions are marked black.

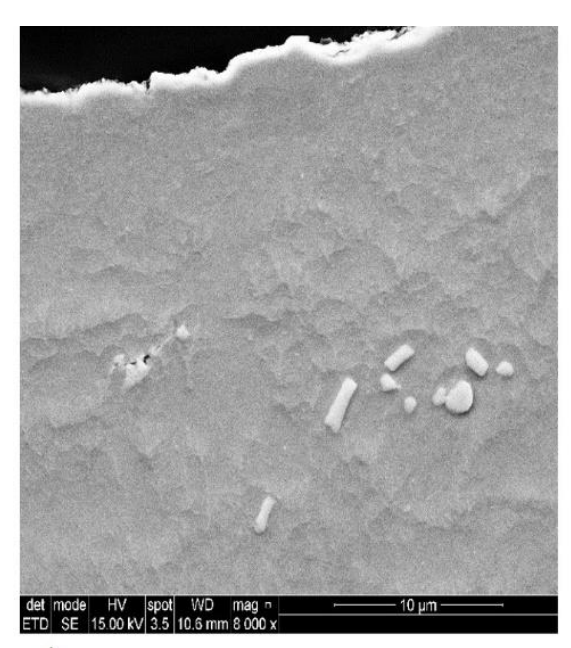

a)

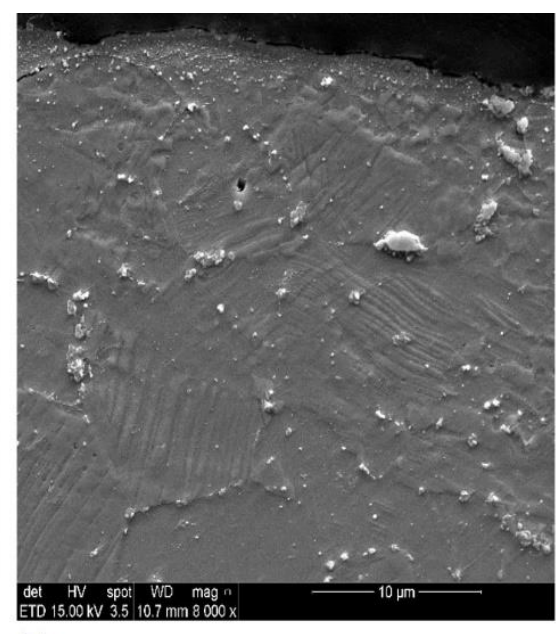

b)

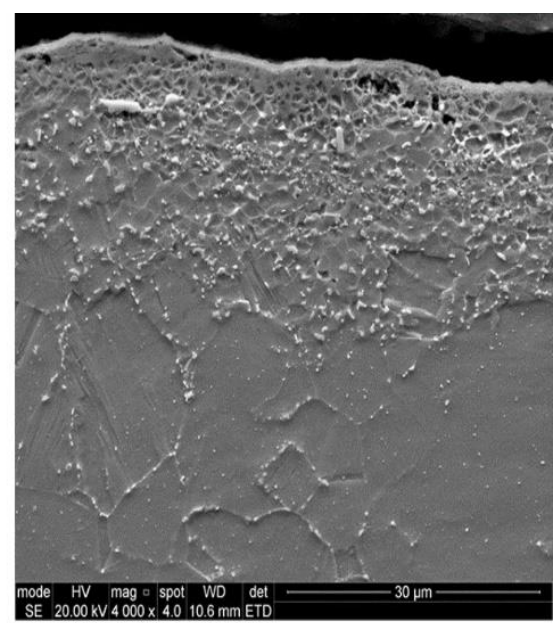

c)

Figure 9: Microstructure of the cross section of the fine grained, shot peened sample after isothermal annealing at $650{ }^{\circ} \mathrm{C}$ (sample FG-SP-650) for $12 \mathrm{~h}$ in $\operatorname{argon}(\mathrm{a}, \mathrm{b})$ or for $168 \mathrm{~h}$ in steam (c). a) corresponds to OPS polishing, b) is etched with glyceregia, c) is etched with Kallings reagent. Figures a) and b) correspond to the same sample as the one used for the EBSD map in Figure 8. 


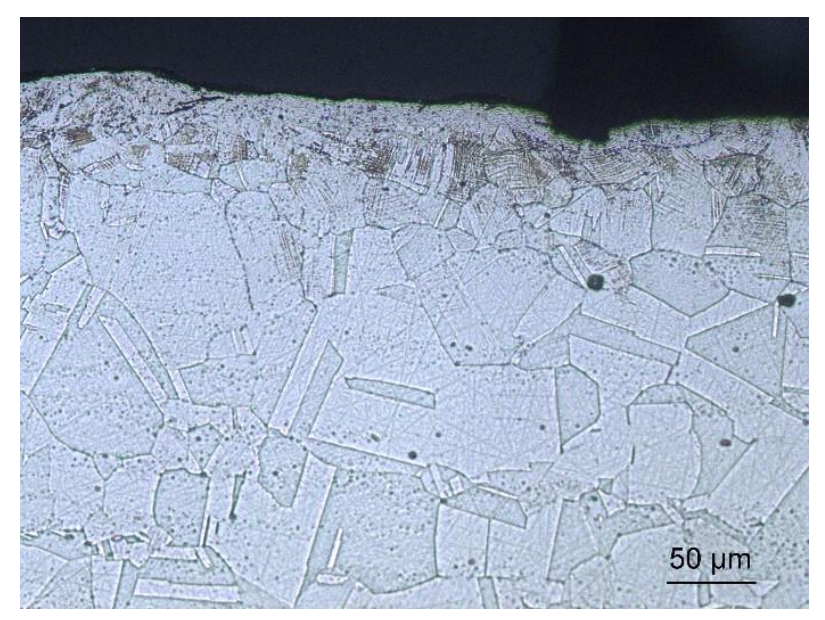

Figure 10: Microstructure of the cross section of a coarse-grained, shot peened steel after isothermal annealing in inert atmosphere at $700{ }^{\circ} \mathrm{C}$ for $0.5 \mathrm{~h}$ (sample CG-SP-700-0.5).

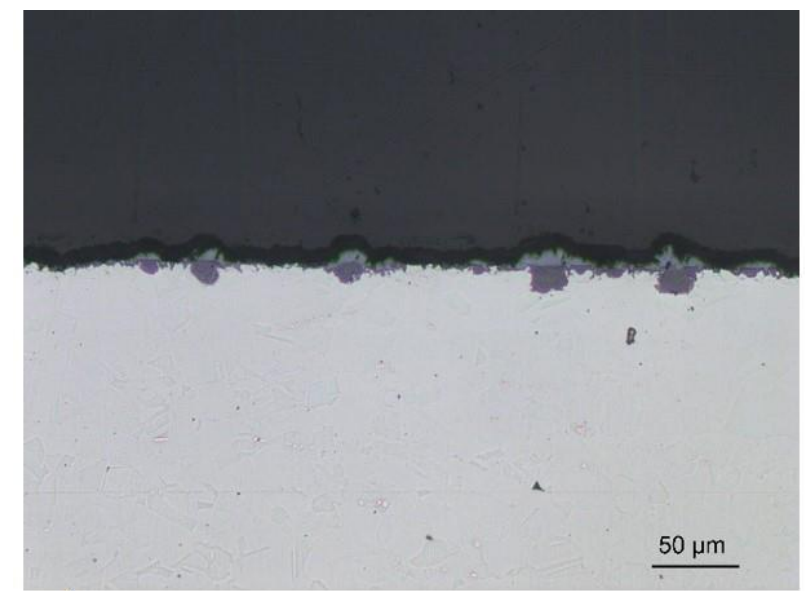

a)

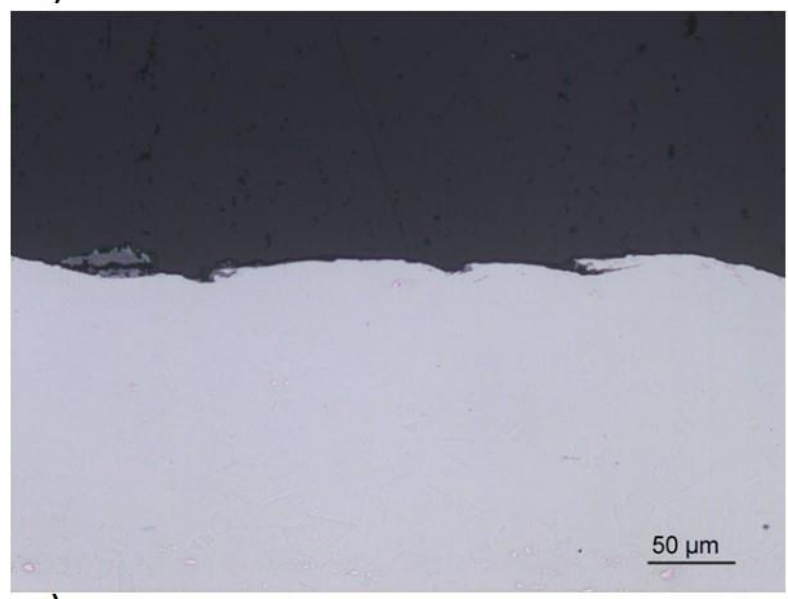

c)

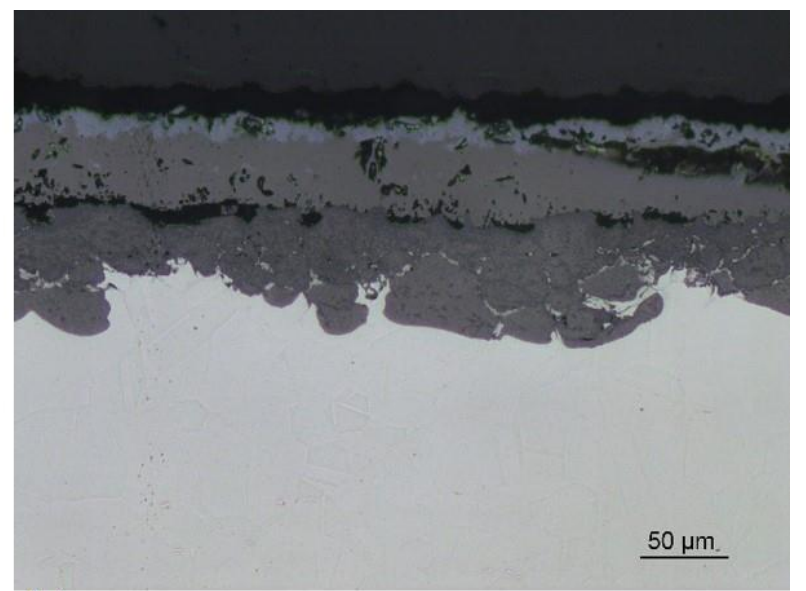

b)

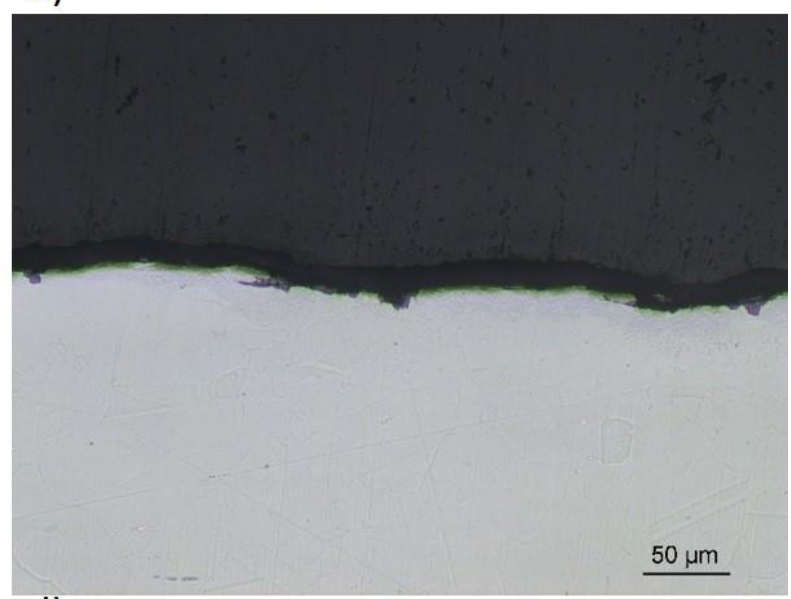

d)

Figure 11: Cross section of the steamside of TP347H tubes after exposure in a Danish power plant for $17000 \mathrm{~h}$ at temperatures of about 550 to $565^{\circ} \mathrm{C}$ for most of the time: a) FG-NSP, b) CG-NSP, c) FG-SP, d) CG-SP. The samples are not etched to focus only on the steamside oxidation. 


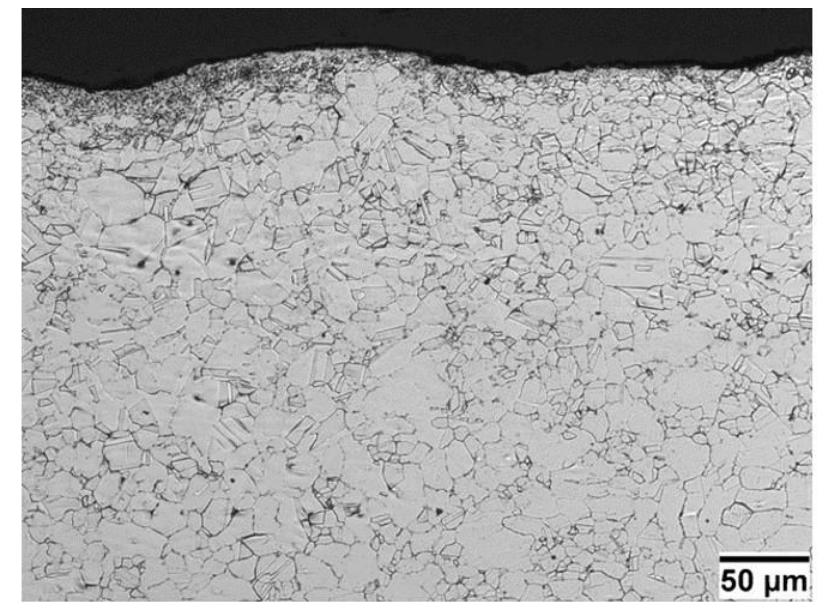

a)

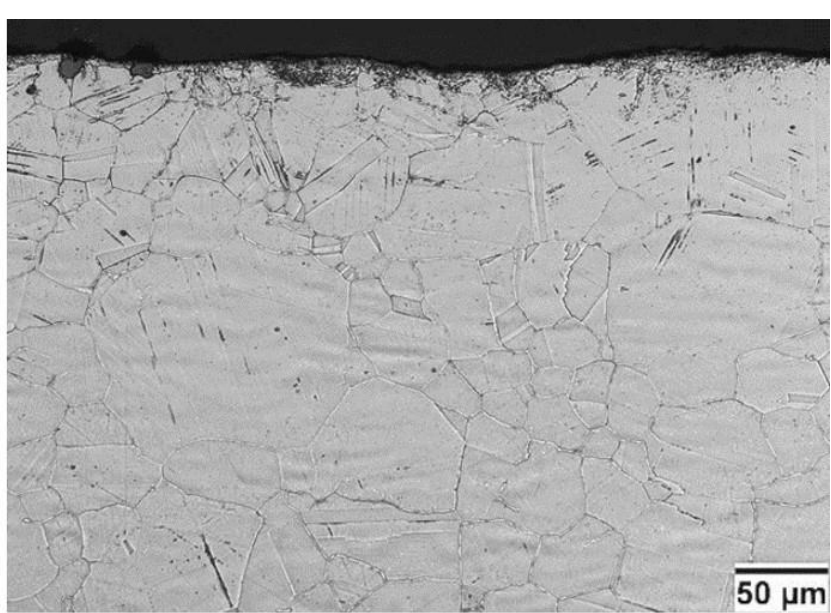

b)

Figure 12: Microstructure after exposure to steam oxidation conditions at $650{ }^{\circ} \mathrm{C}$ for $168 \mathrm{~h}$. a) finegrained, shot peened steel (sample FG-SP-Ox) and b) coarse-grained, shot peened steel (sample CGSP-Ox).

\section{Tables}

Table 1: Chemical composition of TP347H steel in wt.\%, as obtained from energy dispersive X-ray spectroscopy, for both the fine- and coarse-grained samples. The carbon content was not accessible from those measurements. Reference to the steel specification according to ASTM is given.

\begin{tabular}{|l|c|c|c|c|c|c|c|}
\hline TP347H & $\mathrm{Cr}$ & $\mathrm{Ni}$ & $\mathrm{Mn}$ & $\mathrm{Nb}$ & $\mathrm{Si}$ & $\mathrm{C}$ & $\mathrm{Fe}$ \\
\hline fine-grained (FG) & 19.0 & 11.1 & 1.6 & 0.8 & 0.5 & n.a. & balance \\
\hline coarse-grained (CG) & 18.2 & 10.2 & 1.9 & 0.6 & 0.6 & n.a. & balance \\
\hline ASTM A213 & $17.0-19.0$ & $9.0-13.0$ & $<2.0$ & $<1.0$ & $<1.00$ & $0.04-0.10$ & balance \\
\hline
\end{tabular}

